\title{
Let's Keep the Sharing Alive
}

\author{
Sharon F. Terry
}

A GREAT DEAL can be said about the lack of testing in the United States and beyond for COVID-19. There will be abundant time to analyze what happened that made this so difficult. We could rehash the hundreds of things we have talked about especially in the years when genetic testing was emerging.

Instead, I am going to use this space this month to recognize all of the heroic efforts being made in laboratories around the world. These are academic labs and company labs, filled with men and women, who in some sense risk their lives so that we might find ways to manage, contain, quantify and otherwise vanquish COVID-19.

While there are many complaints about the systems we have in place (or don't have in place) here in the United States, many of these are legitimate, and we should take a moment to express gratitude for all those still at their benches and laptops, trying to make this easier for the rest of us.

I am not polly-anna-ish here. I know there are many motives for continuing to develop a test, assay, vaccine, and/or treatments. I also know the good will and compassion, the desire to do good, and help, that is fueling a lot of what is happening as we all face what we could not imagine before this pandemic.

I think of a parable that I heard long ago. Essentially this is the story of someone visiting one room where there is a banquet in progress and no one is eating because the spoons are too long to reach their mouths. Everyone is starving. In a second room, the same banquet, the same long spoons, but everyone is eating, and joyous as a result. They are feeding each other.

I hope that this time of scarcity, extreme sickness and death, "sheltering in place," working from home, and learning what each other's living rooms, kids, and cats look like, will change how we see our worlds. I hope that any of the resource, data, and discovery sharing we have been doing in this time of great stress will become the norm; that we will connect the dots, not just our interconnectivity as a nation and a globe, but our capacity to share, to care for one another, and to establish new ways of working with each other. What if we went back to work and freely shared data? What if we did not worry about protecting our ideas? What if we all did it? Nothing is impossible.

With some likeminded collaborators at LunaDNA, I have set up an experiment in data sharing. We put people at the center, leave them with control of their data (it is not ours to give), enabling them to tell us their experience of having COVID-19 and not having it, connecting electronic health records from any portal in the United States, and sharing their genomic information. The data never leaves the platform so that people always "have a string on their data." It is never sold. And, everyone benefits; all participants receive shares in the com- pany when data is accessed. You can contribute to the cause, your cause, the world's cause at http://www.fighttoendcovid .com. Let's allow this culture of sharing to thrive.

\section{Pandemic}

What if you thought of it as the Jews consider the Sabbath-

the most sacred of times?

Cease from travel.

Cease from buying and selling.

Give up, just for now,

on trying to make the world

different than it is.

Sing. Pray. Touch only those

to whom you commit your life.

Center down.

And when your body has become still,

reach out with your heart.

Know that we are connected

in ways that are terrifying and beautiful.

(You could hardly deny it now.)

Know that our lives

are in one another's hands.

(Surely, that has come clear.)

Do not reach out your hands.

Reach out your heart.

Reach out your words.

Reach out all the tendrils

of compassion that move, invisibly,

where we cannot touch.

Promise this world your love-

for better or for worse,

in sickness and in health, so long as we all shall live.

-Lynn Ungar (Ungar 2020)

\section{Reference}

Ungar L (2020) Pandemic. Available at: http://www.lynnungar .com/poems/pandemic/ (Last accessed April 15, 2020).

Address correspondence to:

Sharon F. Terry, MA

Genetic Alliance

4301 Connecticut Avenue NW-Suite 404

Washington, DC 20008-2304

USA

E-mail: sterry@geneticalliance.org

Genetic Alliance, Washington, District of Columbia, USA. 